\title{
Hypertonic saline jet nebulization breathing treatments produce a predictable quantity of aerosolized sodium chloride for inhalation
}

\author{
Martin J. Flores AS ${ }^{1}$, MaTais Caldwell BS ${ }^{1}$, Kalysa D. Passmore AS ${ }^{1}$, Megan Denney, RRT ${ }^{1}$, James M. Carr ${ }^{2}$, Kerri Carr, FNP-BC ${ }^{1,3}$, \\ Jeremy M. Carr, PhD, M.Ed,
}

\begin{abstract}
MJ Flores, M Caldwell, KD Passmore, M Denney, JM Carr, K Carr, JM Carr. Hypertonic saline jet nebulization breathing treatments produce a predictable quantity of aerosolized sodium chloride for inhalation. Can J Respir Ther 2022;58:15-19. doi: 10.29390/cjrt-2021-055.

Purpose: The amount of sodium chloride $(\mathrm{NaCl})$ that escapes a nebulizer cup, intended for patient inhalation, during a 5-min hypertonic saline jet nebulization (HSJN) breathing treatment is apparently unknown in the pure and applied scientific literature. This study aimed to address this void by focusing on $\mathrm{NaCl}$ mass changes prior to and after a typical HSJN breathing treatment using an ordinary household, medical-grade air compressor.

Research methods: Saline solutions of varying concentrations were nebulized to room air for $5 \mathrm{~min}$. Pre- and post-nebulization $\mathrm{NaCl}$ concentrations were determined from measured conductivities via calibration curve. The resulting data were used to quantify $\mathrm{NaCl}$ mass changed from the beginning and end of a typical HSJN breathing treatment.

Main findings: Conductivity was a reliable metric in $\mathrm{NaCl}$ concentrations ranging from $2.10 \times 10^{-1}$ to $8.16 \times 10^{-3} \mathrm{M}$. Pre- and post-nebulization NaCl mass differences of 19-114 mg linearly correlated with saline concentration (wt\%). The resulting trendline data reasonably predict how much $\mathrm{NaCl}$ is available for patient inhalation during a typical HSJN breathing treatment. Linearity in the data suggests that factors such as colligative properties (e.g., osmolarity) have a minimal influence on the amount of $\mathrm{NaCl}$ that escapes the nebulizer cup.

Conclusions: These results are the first to quantify how much $\mathrm{NaCl}$ escapes a nebulizer cup during a typical HSJN breathing treatment. Furthermore, the results represent a key starting point upon which future studies can be built to explore additional airflow rates, kinetics, and temperature effects. Collectively, these findings will play a critical role in ascertaining the mechanism of action in hypertonic saline breathing treatments.
\end{abstract}

Key Words: hypertonic saline; sodium chloride; jet nebulization; conductivity; respiratory tract

\section{INTRODUCTION}

Jet nebulization is widely regarded as a ubiquitous, cost-effective, and well-tolerated intervention for treating respiratory diseases [1]. Hypertonic saline jet nebulization (HSJN) is a mucolytic, therapeutic subset within this field wherein patients undergoing treatment inhale saltwater droplets. Medical professionals order HSJN breathing treatments to manage symptoms associated with respiratory illnesses [1] including cystic fibrosis [2], tracheostomies [3], and asthma [4]. Despite some skepticism [5], HSJN reduces hospitalization admissions and shortens hospital stay lengths in patients diagnosed with bronchiolitis [6, 7].

During an HSJN treatment, pressurized gas such as room air or oxygen is fed into a jet nebulizer cup containing hypertonic saline-a sodium chloride $(\mathrm{NaCl})$ solution exceeding $0.9 \%$ by mass. Within the cup, the saline is drawn into the gaseous stream, shearing the solution into a mist with a variety of droplet sizes [8]. Larger droplets tend to collide with internal baffling within the nebulizer cup, usually returning into the solution reservoir, whereas microscopic droplets escape the cup and are available for patient inhalation.

Numerous questions remain about hypertonic saline breathing treatments. Apart from the intense, ongoing debate over HSJN's complete mechanism of action $[3,6,9,10]$, relative to albuterol [11] and arformoterol [12], little has been reported about HSJN. By extension, the scientific and medical literature apparently have yet to address the question of drug delivery-quantifying the amount of $\mathrm{NaCl}$ escaping the nebulizer cup. Our objective for this study was to determine drug output as a patient undergoes a typical HSJN breathing treatment.

Herein, we report, via laboratory simulation, pre-and post-nebulization $\mathrm{NaCl}$ mass differences via conductivity measurement using a portable, medical-grade air compressor. The term "typical" as used in this paper is defined as $5.0 \mathrm{~min}$. This definition is entirely semantic and is used primarily to help clarify language. Moreover, a 5-min breathing treatment reflects recent literature [13] describing patient preference for shorter nebulization times.

${ }^{1}$ Central Alabama Community College, Alexander City, AL

${ }^{2} \mathrm{KeBa}$, LLC, Research Division, Dadeville, AL

${ }^{3}$ Neurology Consultants of Montgomery, Montgomery, AL

Correspondence: Jeremy M. Carr, Chemistry Department Chair, Central Alabama Community College, 1675 Cherokee Road, Alexander City, AL, 35010 , United States of America. Tel: +1 256-215-4342, E-mail: jcarr@cacc.edu.

Published online at https://www.cjrt.ca on 8 February 2022

This open-access article is distributed under the terms of the Creative Commons Attribution Non-Commercial License (CC BY-NC) (http:// creativecommons.org/licenses/by-nc/4.0/), which permits reuse, distribution and reproduction of the article, provided that the original work is properly cited and the reuse is restricted to noncommercial purposes. For commercial reuse, contact editor@csrt.com 


\section{FIGURE 1}

Raw conductivity measurements in this study were converted to sodium chloride mass quantities using a series of conversions.

\begin{tabular}{|c|c|c|c|c|c|c|}
\hline $\begin{array}{l}\text { Conductivity } \\
\text { Measurement } \\
\left.(\mu \mathrm{S} \mathrm{cm})^{-1}\right)\end{array}$ & $\underset{\text { Curve }}{\stackrel{\text { Calibration }}{\longrightarrow}}$ & $\begin{array}{l}\text { Sodium Chloride } \\
\text { Concentration } \\
\left.\text { (moles } L^{-1}\right)\end{array}$ & $\underset{\text { Volume }(\mathrm{L})}{\stackrel{\text { Solution }}{\longrightarrow}}$ & $\begin{array}{c}\text { Sodium Chloride } \\
\text { Quantity } \\
\text { (moles) }\end{array}$ & $\underset{\text { Mass }}{\stackrel{\text { Molar }}{\longrightarrow}}$ & $\begin{array}{c}\text { Sodium Chloride } \\
\text { Quantity } \\
\text { ( } g \text { then } m g \text { ) }\end{array}$ \\
\hline
\end{tabular}

\section{TABLE 1}

\section{Various $\mathrm{NaCl}$ and distilled water masses utilized for solution preparation in this study}

\begin{tabular}{lccc}
\hline $\begin{array}{l}\text { Saline concentration } \\
\text { (mass } \%)\end{array}$ & $\begin{array}{c}\mathbf{N a C l} \text { mass } \\
(\mathbf{g})\end{array}$ & $\begin{array}{r}\text { Distilled water mass } \\
(\mathbf{g})\end{array}$ & $\begin{array}{c}\text { Solution molarity } \\
\left(\mathbf{m o l ~ L}^{-1}\right)\end{array}$ \\
\hline 0.9 & 0.900 & 99.1 & 0.0154 \\
3 & 3.00 & 97.0 & 0.0514 \\
5 & 5.00 & 95.0 & 0.0856 \\
7 & 7.00 & 93.0 & 0.120 \\
9 & 9.00 & 91.0 & 0.154 \\
12 & 12.00 & 88.0 & 0.205
\end{tabular}

Note: Resulting solution molarities were calculated from solute and solvent masses assuming the saline density did not exceed $1.00 \mathrm{~g} \mathrm{~mL}^{-1}$ [14].

\section{MATERIALS AND METHODS}

\section{Saline solutions}

All saline solutions were prepared from reagent-grade $\mathrm{NaCl}$ (Fisher Scientific, >99.9\%) and distilled water. Saline nebulizer solution concentrations were selected according to their prescription availability within North America and thus were prepared as mass percentages in the concentrations of $0.9 \%, 3 \%, 5 \%, 7 \%, 9 \%$, and $12 \%$ (Table 1 ). All solute quantities analyzed were expressed as molar concentrations (i.e., moles of solute per liter of solution) with the assumption that saline solution density did not exceed $1.00 \mathrm{~g} \mathrm{~mL}^{-1}[14]$.

\section{Nebulization setup}

Saline solutions were nebulized using a disposable jet nebulizer cup/lid (Sunset Healthcare Solutions, model RES091) and Rite-Neb 3 Nebulizer Compressor (Probasics, model 8005LP3), a model commonly found in many North American homes. Manufacturer specifications indicate the maximum compressor flow rate was between $8 \mathrm{~L} \mathrm{~min}^{-1}$ and $11 \mathrm{~L} \mathrm{~min}^{-1}$. The typical output flow rate for this study was between $10 \mathrm{~L} \mathrm{~min}^{-1}$ and $11 \mathrm{~L} \mathrm{~min}^{-1}$, measured with a Gentech $\mathrm{O}_{2}$ flow rate meter (model FM197A-15L-DS). The nebulizer cup and compressor system had a measured operating flow rate of $5 \mathrm{~L} \mathrm{~min}^{-1}$, which is consistent with comparable systems [12].

\section{Typical nebulization experiment}

For each nebulization experiment, a $4.0 \mathrm{~mL}$ saline aliquot was added via a class A volumetric pipette to a clean, dry jet nebulizer cup connected to an air compressor. Within the United States, HSJN breathing treatment saline is packaged in $4.0 \mathrm{~mL}$ volumes. Each sample was nebulized to laboratory air (mean pressure and temperature: $0.987 \mathrm{~atm}$ and $23.1^{\circ} \mathrm{C}$, respectively) for exactly $5.0 \mathrm{~min}$. Factors such as room temperature are known to influence particle size and mean output during nebulization [15].

Similar to existing literature [16], after nebulization, the remaining solution within the nebulizer cup was transferred to a $25.0 \mathrm{~mL}$ volumetric flask. The jet nebulizer cup and lid were rinsed portion-wise with distilled water $(3 \times 2 \mathrm{~mL})$. All rinses were combined in a volumetric receiving flask, and the resulting solution was diluted to mark, capped, and inverted 21 times to ensure homogeneity. Analyte solutions were prepared by pouring $\sim 8 \mathrm{~mL}$ aliquots into $2 \mathrm{~cm} \times 15 \mathrm{~cm}$ glass test tubes.

\section{Solution analysis}

All solution conductivities were analyzed via conductivity probe (Vernier, model CON-DIN) and data collected using Logger Lite software (version 1.9.4) under gentle agitation until the measured value remained unchanged for $15 \mathrm{~s}$. Each sample was measured in triplicate, and the average value was utilized in this study. Initial investigations indicated that measured conductivities in excess of $190.3 \mu \mathrm{S} \mathrm{cm}^{-1}$ and below $2.6 \mu \mathrm{S} \mathrm{cm}-1$ inaccurately correlated with solution concentration. Thus, samples in excess of $190.3 \mu \mathrm{S} \mathrm{cm}^{-1}$ were appropriately diluted with distilled water such that the measured conductivity fell within the probe's linear dynamic range. The conductivity probe was calibrated daily against standard solutions and did not exhibit drifting throughout this study.

\section{Data analysis}

Absolute conductivity measurements were mathematically converted to $\mathrm{NaCl}$ masses according to Figure 1. Although gravimetric analysis is not an ideal method for this type of study, actual laboratory mass measurement was performed in solution preparation only; all other measurements were volumetric or conductivity. References to mass throughout this paper were utilized to quantify the amount of drug a patient could potentially receive during HSJN breathing treatments.

Prior to experimentation, a calibration curve comparing measured conductivity against $\mathrm{NaCl}$ concentration was developed and utilized to convert between microsiemens per centimeter $\left(\mu \mathrm{S} \mathrm{cm}{ }^{-1}\right)$ and molarity (M) dimensions. Then, based on analyte volumes, solution concentrations were converted into moles, and subsequently into mass using the $\mathrm{NaCl}$ average atomic weight molar mass $\left(58.44 \mathrm{~g} \mathrm{~mol}^{-1}\right)$. All mass values in this study were reported in milligrams ( $\mathrm{mg}$ ).

In this study, "nebulized" saline was equated with solute mass difference ( $\Delta$ Mass) between mean pre-nebulization (Mass) and post-nebulization $\left(\right.$ Mass $_{f}$ ) experiments as $\Delta$ Mass $=$ Mass $_{f}-$ Mass $_{i}$. Note that masses were calculated directly from conductivity measurements according to Figure 1. We assumed that the term "nebulized" referred to sodium chloride that had escaped the nebulizer cup into the laboratory. Although "escaped the nebulizer cup" does not mean "inhaled", the generated mist is, in essence, available for patient inhalation. The quantity of $\mathrm{NaCl}$ a patient receives could be the subject of future, follow-up studies.

Each solution was analyzed at least 3 times to ensure that an average $\mathrm{NaCl}$ mass and corresponding standard deviation could be calculated. All data collected in this experiment were evaluated using Microsoft Excel 2018 (version 16.16.18). Experimental data are available for review in the Supplementary Material ${ }^{1}$. In instances where relative error exceeded 5\%, the data set was examined via Grubbs test to identify potential outliers with $95 \%$ confidence. These data points were removed, and averages/standard deviations were recalculated.

\section{RESULTS}

\section{Calibration curve}

The conductivity/ $\mathrm{NaCl}$ concentration correlation for this study (Figure 2) was assumed to be linear. The resulting trendline

\footnotetext{
${ }^{1}$ Supplementary Material is available on the journal website at: https://www. cjrt.ca/wp-content/uploads/Supplement-cjrt-2021-055.pdf.
} 


\section{FIGURE 2}

Calibration curve used to relate measured conductivity ( $\mu S \mathrm{~cm}^{-1}$ ) in aqueous saline samples to the corresponding concentration (M).

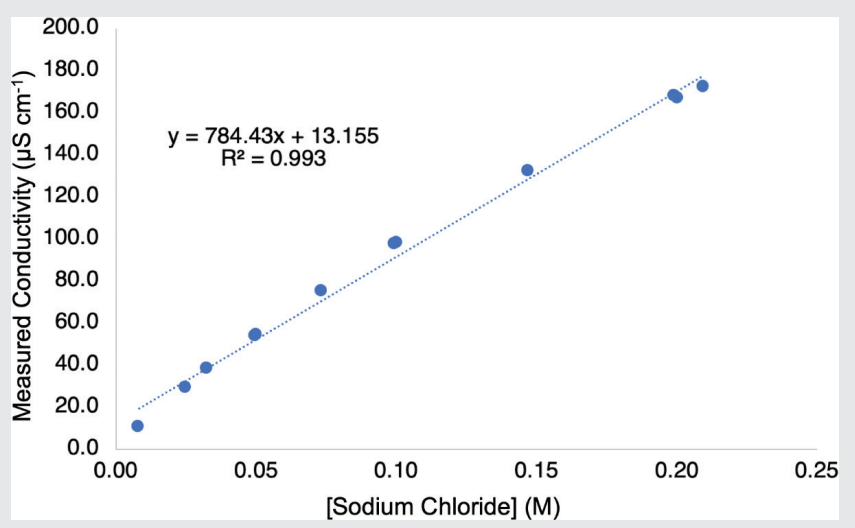

TABLE 2

Compiled experimental data showing average $\mathrm{NaCl}$ masses prior to and following 5.0 min of jet nebulization

\begin{tabular}{|c|c|c|c|c|c|c|c|c|c|c|c|c|}
\hline \multicolumn{5}{|c|}{ Pre-nebulization } & \multicolumn{4}{|c|}{ Post-nebulization } & \multicolumn{4}{|c|}{ Difference } \\
\hline $\begin{array}{l}\text { Saline } \\
\text { concentration } \\
(w t \%)\end{array}$ & $\begin{array}{l}\text { Mean } \mathrm{NaCl} \\
\text { mass }(\mathrm{mg})\end{array}$ & $\begin{array}{l}\text { Standard } \\
\text { deviation } \\
\text { (mg) }\end{array}$ & $\begin{array}{l}\text { Upper } \\
\text { range } \\
(\mathrm{mg})\end{array}$ & $\begin{array}{l}\text { Lower } \\
\text { range }(\mathrm{mg})\end{array}$ & $\begin{array}{l}\text { Mean } \mathrm{NaCl} \\
\text { mass (mg) }\end{array}$ & $\begin{array}{c}\text { Standard } \\
\text { deviation } \\
\text { (mg) }\end{array}$ & $\begin{array}{c}\text { Upper } \\
\text { range }(\mathrm{mg})\end{array}$ & $\begin{array}{c}\text { Lower } \\
\text { range (mg) }\end{array}$ & $\begin{array}{l}\text { Mean } \mathrm{NaCl} \\
\text { mass }(\mathrm{mg})\end{array}$ & $\begin{array}{c}\text { Standard } \\
\text { deviation } \\
(\mathrm{mg})\end{array}$ & $\begin{array}{l}\text { Upper } \\
\text { range }(\mathrm{mg})\end{array}$ & $\begin{array}{c}\text { Lower } \\
\text { range }(\mathrm{mg})\end{array}$ \\
\hline 0.9 & 37.1 & 0.2 & 37.3 & 37.0 & 19 & 3 & 23 & 14 & 19 & 3 & 23 & 14 \\
\hline 3.0 & 136 & 3 & 140 & 134 & 105 & 6 & 116 & 98 & 31 & 6 & 38 & 20 \\
\hline 5.0 & 230 & 9 & 242 & 218 & 176 & 2 & 178 & 174 & 54 & 2 & 56 & 52 \\
\hline 7.0 & 295 & 5 & 303 & 289 & 230 & 6 & 236 & 223 & 64 & 6 & 71 & 58 \\
\hline 9.0 & 418 & 4 & 421 & 413 & 319 & 8 & 330 & 311 & 100 & 8 & 107 & 88 \\
\hline 12.0 & 569 & 6 & 574 & 558 & 457 & 11 & 472 & 434 & 114 & 12 & 135 & 97 \\
\hline
\end{tabular}

Note: The final shaded column shows the average difference between post-nebulization and mean pre-nebulization masses. Each experiment was performed at least three times to report an average, range, and standard deviation.

$\left(y=784.43 \mu \mathrm{S} \mathrm{cm}^{-1} \mathrm{M}^{-1}(x)+13.155 \mu \mathrm{S} \mathrm{cm}{ }^{-1}\right)$ exhibited a coefficient of determination of 0.993 . Conductivities ranging from 172.3 to $10.3 \mu \mathrm{S} \mathrm{cm} \mathrm{cm}^{-1}$ correlated with saline concentrations ranging from $2.10 \times 10^{-1}$ to $8.16 \times 10^{-3} \mathrm{M}$, respectively. Concentrations exceeding $2.10 \times 10^{-1} \mathrm{M}$ were found to deviate from the established linear trend. Similarly, saline concentrations below $8.16 \times 10^{-3} \mathrm{M}$ gave inaccurate conductivity values. For instance, when $1.03 \times 10^{-3} \mathrm{M}$ saline and distilled water were both analyzed, both exhibited conductivities of $0.5 \mu \mathrm{S} \mathrm{cm}^{-1}$.

\section{Nebulization experiments}

Results from nebulization experiments appear in Table 2. Prenebulization solution conductivities gave average $\mathrm{NaCl}$ masses ranging from $37 \mathrm{mg}$ to $569 \mathrm{mg}$ with standard deviations of $0.2 \mathrm{mg}$ and $9 \mathrm{mg}$, respectively. After $5.0 \mathrm{~min}$ of nebulization, conductivity measurements indicated that solute masses ranged from $19 \mathrm{mg}$ to $457 \mathrm{mg}$ with standard deviations ranging from $2 \mathrm{mg}$ to $11 \mathrm{mg}$, respectively. The differences in $\mathrm{NaCl}$ masses between pre- and post-nebulization ranged from $19 \mathrm{mg}$ to $114 \mathrm{mg}$, with corresponding standard deviations ranging from $2 \mathrm{mg}$ to $12 \mathrm{mg}$, respectively.

Pre- and post-nebulization mass differences strongly correlated with initial saline concentration (Figure 3 ). The resulting linear trend $\left(y=912.76 \mathrm{mg}^{-1}(x)+7.39 \mathrm{mg}\right)$ exhibited a coefficient of determination of 0.974. Error bars reported in Figure 3 represent the standard deviations of mass differences. For this study, the trendline passed through nearly all error bars, which is consistent with linearity. Apart from the anomalously low error for our $5.0 \%$ saline solutions, standard deviations tended to increase with initial saline concentration. Based on existing literature [12], these results are comparable to similar, portable HSJN systems available for home, clinic, and hospital use.

Figure 3 also indicates that for a 5 -min saline breathing treatment, the amount of $\mathrm{NaCl}$ escaping the nebulizer cup is predictable. For instance, the trendline in Figure 3 predicts that over a 5-min breathing treatment, a $4.0 \mathrm{~mL}$ sample of $5.0 \%$ saline produces $53 \mathrm{mg}$ of sodium chloride. This result is $1 \mathrm{mg}$, or $2 \%$, different from the laboratory result. The comparison between actual and predicted values (Table 3) shows that these absolute percent differences range from $2 \%$ to $16 \%$, where the largest deviations tended to occur for the most dilute solutions, variations that are consistent with existing literature [16]. The average percent difference between the actual and predicted values in Table 3 was 9\%. Collectively, these results suggest that our data plot provides a reasonable model for predicting saline output for a typical jet nebulization breathing treatment.

\section{DISCUSSION}

Clinical relevance

Because HSJN breathing treatments can disrupt ionic interactions within mucus gel [17], higher concentration saline solutions likely cause enhanced mucolytic properties and even improved patient outcomes. It is also well known that nebulized saline triggers coughing reflexes [17], which are beneficial to sputum clearance but could be potentially 


\section{FIGURE 3}

Scatter plot comparing the average difference between pre- and post-nebulization $\mathrm{NaCl}$ mass differences (mg) versus saline concentration (wt\%). Reported error bars are the range of pre- and post-nebulization $\mathrm{NaCl}$ mass differences for each initial saline concentration.

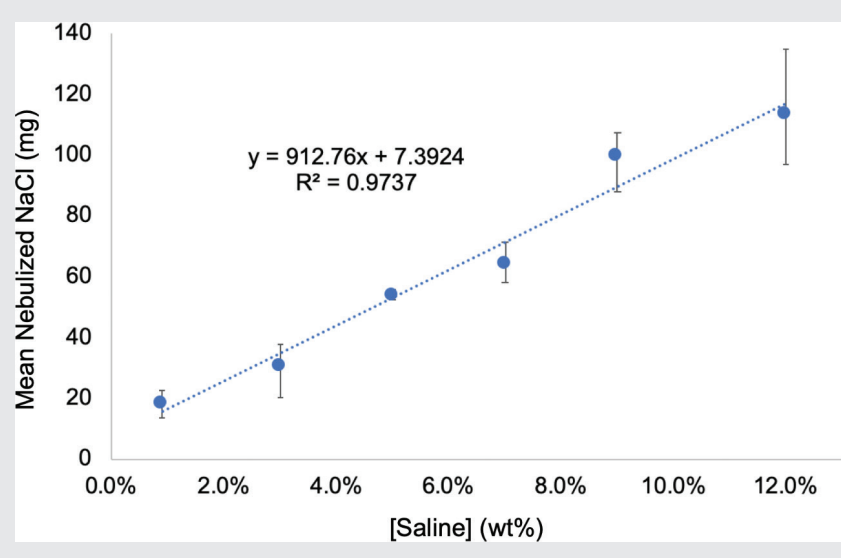

TABLE 3

Comparison of actual sodium chloride mass difference experimental data and predicted experimental data from trendline data in Figure 2

\begin{tabular}{|c|c|c|c|c|}
\hline Saline concentration (wt $\%$ ) & $\begin{array}{c}\text { Actual mean } \mathrm{NaCl} \text { mass } \\
\text { difference }(\mathrm{mg})\end{array}$ & $\begin{array}{l}\text { Predicted mean } \mathrm{NaCl} \text { mass } \\
\text { difference }(\mathrm{mg})\end{array}$ & $\begin{array}{l}\text { Absolute difference } \\
\qquad(\mathrm{mg})\end{array}$ & $\begin{array}{l}\text { Predicted mass } \\
\text { percent difference }\end{array}$ \\
\hline 0.9 & 19 & 16 & 3 & 16 \\
\hline 3.0 & 31 & 35 & 4 & 13 \\
\hline 5.0 & 54 & 53 & 1 & 2 \\
\hline 7.0 & 64 & 71 & 7 & 11 \\
\hline 9.0 & 100 & 90 & 10 & 10 \\
\hline 12.0 & 114 & 117 & 3 & 3 \\
\hline
\end{tabular}

detrimental to patients. For example, a patient with pseudotumor cerebri who has comorbid conditions requiring the use of mucolytics proposes a unique challenge. With pseudotumor cerebri, not only is the patient on a strict salt-intake limit, but symptoms are also exacerbated by triggers such as prolonged coughing [18], which will likely result in irreversible blindness if left uncontrolled. Consequently, providers must evaluate the gain of utilizing HSJN versus the risk of triggering a life-altering cough. Our findings can help clinicians precisely determine the quantity of $\mathrm{NaCl}$ a patient could potentially receive during a 5-min breathing treatment based on the initial saline concentration.

\section{Colligative effects}

The linear data trends offer input as to whether colligative effects influence HSJN output. Because colligative properties such as surface tension $[19,20]$ and viscosity $[14,21]$, general factors of drug-related performance [16], are directly related to solute concentration, we anticipated that these effects might influence the amount of $\mathrm{NaCl}$ being produced for patient inhalation [22]. However, the linear trend in Figure 2 suggests that HSJN is, at operating flow rate of $5 \mathrm{~L} \mathrm{~min}^{-1}$, minimally influenced by colligative properties. If colligative properties play a role in aerosol generation, the force of compressed air acting upon the saline solution likely negates any observable effect.

\section{Comparison/contrast with existing literature}

The results from this study bear some similarities with existing literature. For example, similar studies tended to utilize homecare nebulizer setups [12], dilute samples to an appropriate concentration prior to nebulization [11] or during post-nebulization sample collection, prior to analysis [16].
However, there are novel differences between our study and existing literature. Key prior studies relied entirely upon gravimetric analysis $[16,23]$ to evaluate drug delivery efficiency or output droplet size. Other studies evaluated the nebulization of organic-based, spectrophotometrically active molecules $[11,12,16]$. Our use of conductivity and volumetric measurements to evaluate drug output offers the medical community an inexpensive strategy for studying HSJN reliably.

Study limitations and future work

Although our study measured $\mathrm{NaCl}$ outputs at 5-min intervals, the HSJN kinetic aspects-how solution conductivity (and, by extension, mass) changes over time-have yet to be addressed in the scientific and/ or medical literature. Currently, our group is in the process of devising an experimental plan for evaluating this aspect of HSJN with the goal of establishing a process (i.e., reaction) order, an apparent void in the scientific and medical literature.

Another limitation of our study was the sole use of jet nebulizers with portable air compressors. One reoccurring theme throughout the literature $[23,24]$ was an output comparison between traditional jet nebulization versus vibrating mesh technologies. Thus, future work could involve a conductivity probe analysis that evaluates the performance of jet nebulizers versus vibrating mesh nebulized saline solutions or even metered doses.

Li et al. [25] recently opined that the physical and chemical properties of aerosols, and their generation in medical application, remain largely unevaluated and warrant further investigation. The fact that colligative properties play an apparent role in the nebulization of a solution $[14,16,19-21]$ warrants how these effects influence HSJN. Although 
one obvious extension of studying these effects is to vary output flow rate, contributions from the carrier gas (i.e., air vs. pure oxygen) could also prove useful in the development of improved technologies.

Finally, although many nebulization studies are performed in vitro, our solutions were nebulized to room air rather than into an adult lung bench model [12, 23, 24]. Because mist that escapes the nebulizer cup is only available for patient inhalation, another follow-up study could precisely examine how much $\mathrm{NaCl}$ a patient receives during a typical breathing treatment.

\section{CONCLUSION}

We sought to determine exactly how much $\mathrm{NaCl}$ escaped the nebulizer cup during a 5-min HSJN breathing treatment. Pre- and post-nebulization $\mathrm{NaCl}$ mass differences indicated that between $19 \mathrm{mg}$ and $114 \mathrm{mg}$ of $\mathrm{NaCl}$ escaped the nebulizer cup, depending upon the initial saline concentration. The resulting regression analysis reliably predicts how much $\mathrm{NaCl}$ is likely to escape the nebulizer cup during a typical breathing treatment. Linearity in the data suggests that colligative properties (e.g., osmolality) minimally affect the quantity of $\mathrm{NaCl}$ that escaped the nebulizer cup. To our knowledge, these findings are the first quantitative report on pre- and post-nebulization $\mathrm{NaCl}$ mass differences during HSJN breathing treatments. The potential applications of these findings are boundless, this seminal work represents a key step in definitively determining how much $\mathrm{NaCl}$ a patient could potentially receive during a typical breathing treatment.

\section{ACKNOWLEDGMENTS}

The authors wish to thank Kaylen Thomas (Encompass Health Corporation) for her donation of jet nebulizer equipment.

\section{DISCLOSURES}

\section{Contributors}

MC, MJF, KDP were primarily responsible for collecting laboratory data. MC, MJF, KDP, JMC, and JMC were responsible for study design and data analysis. KEHC and MD were responsible for providing clinical applications for collected data. JMC and JMC were responsible for literature searching, manuscript preparation/review/editing, and project supervision.

\section{Competing Interests}

The authors declare no conflict of interest.

\section{Funding}

This study did not receive any specific grant from funding agencies in the public, commercial, or not-for-profit sectors.

\section{Ethical Approval}

Not required.

\section{REFERENCES}

1. Ari A. Jet, ultrasonic, and mesh nebulizers: an evaluation of nebulizers for better clinical outcomes. Eur J Pulmonol 2014;16:1-7. doi: 10.5152/ ejp.2014.00087.

2. Elkins MR, Robinson M, Rose BR, et al. A controlled trial of long-term inhaled hypertonic saline in patients with cystic fibrosis. New Engl J Med 2006;354(3):229-40. doi: 10.1056/nejmoa043900.

3. Wen Z, Wu C, Cui F, Zhang H, Mei B, Shen M. The role of osmolality in saline fluid nebulization after tracheostomy: time for changing? BMC Pulm Med 2016;16(1):179. doi: 10.1186/s12890-016-0342-x.

4. Daviskas E, Anderson SD, Gonda I, et al. Inhalation of hypertonic saline aerosol enhances mucociliary clearance in asthmatic and healthy subjects. Eur Resp J 1996;9(4):725-32. doi: 10.1183/09031936.96.09040725.

5. Harrison W, Angoulvant F, House S, Gajdos V, Ralston SL. Hypertonic saline in bronchiolitis and type I error: a trial sequence analysis. Pediatrics 2018;142(3):e2018114. doi: 10.1542/peds.2018-1144.

6. Wu S, Baker C, Lang ME, et al. Nebulized hypertonic saline for bronchiolitis. JAMA Pediatr 2014;168(7):657. doi: 10.1001/ jamapediatrics.2014.301.

7. Zhang L, Mendoza-Sassi RA, Klassen TP, Wainwright C. Nebulized hypertonic saline for acute bronchiolitis: a systematic review. Pediatrics 2015;136(4):687-701. doi: 10.1542/peds.2015-1914.

8. Ari A, Atalay OT, Harwood R, Sheard MM, Aljamhan EA, Fink JB. Influence of nebulizer type, position, and bias flow on aerosol drug delivery in simulated pediatric and adult lung models during mechanical ventilation. Respir Care 2010;55(7):845-51.

9. Gupta HV, Gupta VV, Kaur G, et al. Effectiveness of 3\% hypertonic saline nebulization in acute bronchiolitis among Indian children: a quasi-experimental study. Perspect Clin Res 2016;7(2):88-93. doi: 10.4103/2229-3485.179434.

10. Postiaux G, Zwaenepoel B, Louis J. Chest physical therapy in acute viral bronchiolitis: an updated review. Respir Care 2013;58(9):1541-5. doi: 10.4187/respcare.01890.

11. Diot P, Morra L, Smaldone GC. Albuterol delivery in a model of mechanical ventilation. Comparison of metered-dose inhaler and nebulizer efficiency. Am J Respir Crit Care Med 1995;152(4):1391-4. doi: 10.1164/ajrccm.152.4.7551401.

12. Bauer A, McGlynn P, Bovet LL, Mims PL, Curry LA, Hanrahan JP. Output and aerosol properties of 5 nebulizer/compressor systems with arformoterol inhalation solution. Respir Care 2009;54(10):1342-7.

13. Arunthari V, Bruinsma RS, Lee AS, Johnson MM. A prospective, comparative trial of standard and breath-actuated nebulizer: efficacy, safety, and satisfaction. Respir Care 2012;57(8):1242-7. doi: 10.4187/ respcare. 01450.

14. Kestin J, Shankland IR. Viscosity of aqueous $\mathrm{NaCl}$ solutions in the temperature range $25-200^{\circ} \mathrm{C}$ and in the pressure range $0.1-30 \mathrm{MPa}$. Int J Thermophys 1984;5(3):241-63. doi: 10.1007/bf00507835.

15. Kongerud J, Soyseth V, Johansen B. Room temperature influences output from the Wright jet nebulizer. Eur Respir J 1989;2(7):681-4.

16. Hardaker LEA, Hatley RHM. In vitro characterization of the I-neb Adaptive Aerosol Delivery (AAD) system. J Aerosol Med Pulm Drug Deliv 2010;23(s1):S11-S20. doi: 10.1089/jamp.2009.0792.

17. Elkins MR, Bye PT. Mechanisms and applications of hypertonic saline. J Roy Soc Med 2011;104(1_suppl):2-5. doi: 10.1258/JRSM.2011.S11101.

18. Chan TL, Kim DD, Sharma M, Lee DH, Fraser JA. Valsalva-triggered pseudotumor cerebri syndrome. Neurology 2018;91(8):e746-50. doi: 10.1212/wnl.0000000000006048.

19. Nayar KG, Panchanathan D, McKinley GH, Lienhard JH. Surface tension of seawater. J Phys Chem Ref Data 2014;43(4):043103. doi: 10.1063/1.4899037.

20. Weissenborn PK, Pugh RJ. Surface tension and bubble coalescence phenomena of aqueous solutions of electrolytes. Langmuir 1995;11(5): 1422-6. doi: 10.1021/la00005a002.

21. McCallion ONM, Taylor KMG, Thomas M, Taylor AJ. Nebulization of fluids of different physicochemical properties with air-jet and ultrasonic nebulizers.PharmRes 1995;12(11):1682-8.doi:10.1023/A:1016205520044.

22. O'Callaghan C, Barry PW. The science of nebulised drug delivery. Thorax 1997;52(Suppl 2):S31-S44. doi: 10.1136/thx.52.2008.s31.

23. Michotte JB, Staderini E, le Pennec D, et al. In vitro comparison of a vibrating mesh nebulizer operating in inspiratory synchronized and continuous nebulization modes during noninvasive ventilation. J Aerosol Med Pulm Drug Deliv 2016;29(4):328-36. doi: 10.1089/jamp.2015.1243.

24. Li J, Wu W, Fink JB. In vitro comparison between inspiration synchronized and continuous vibrating mesh nebulizer during trans-nasal aerosol delivery. Intensive Care Med Exp 2020;8(1):6. doi: 10.1186/ s40635-020-0293-7.

25. Li J, Fink JB, Ehrmann S. Author's reply on high-flow nasal cannula for COVID-19 patients: low risk of bio-aerosol dispersion. Eur Respir J 2020;56(4):2003136. doi: 10.1183/13993003.03136-2020. 